\title{
Prophylactic use of tranexamic acid for reducing postpartum hemorrhage in vaginal delivery
}

\author{
Anusha Ginjupalli ${ }^{1 *}$, Anuradha S. N. ${ }^{2}$, Joshi Suyajna D. ${ }^{1}$
}

\author{
${ }^{1}$ Department of Obstetrics and Gynecology, District Hospital, Ballari, Karnataka, India \\ ${ }^{2}$ Department of Obstetrics and Gynecology, J.J.M. Medical College and Hospital, Davanagere, Karnataka, India
}

Received: 01 February 2021

Accepted: 06 March 2021

\author{
*Correspondence: \\ Dr. Anusha Ginjupalli, \\ E-mail: anush617an@gmail.com
}

Copyright: ( ) the author(s), publisher and licensee Medip Academy. This is an open-access article distributed under the terms of the Creative Commons Attribution Non-Commercial License, which permits unrestricted non-commercial use, distribution, and reproduction in any medium, provided the original work is properly cited.

\section{ABSTRACT}

Background: The use of anti-fibrinolytic therapy has potential to reduce obstetric blood loss due to profound changes that take place in the fibrinolytic system during normal childbirth. Objective was to evaluate the efficacy of tranexamic acid in reducing postpartum hemorrhage (PPH) during normal labour.

Methods: Patients who planned for normal delivery and fulfilling the inclusion criteria were recruited for the study. The pre-delivery parameters -pulse rate, blood pressure, $\mathrm{Hb}$ gm $\%$ and $\mathrm{PCV} \%$ were measured for each patient. The study group received injection oxytocin $(10 \mathrm{IU})$ and injection tranexamic acid $(500 \mathrm{mg})$ slow intravenous route. The control group received injection oxytocin (10 IU) and placebo injection. Immediately after delivery of the anterior shoulder of the baby, when all the liquor was drained, Brasse-V drape is placed under the patient. Then the patient was given pre-weighed pads, which were weighed 2 hours post-partum. Final blood loss was calculated by combining amount of blood collected in the drape and blood absorbed by the pads.

Results: The total number of patients studied was 300- equally distributed in both the groups. There was a significant increase in the pulse rate and decrease in blood pressure in the control group compared to the study group. The postdelivery haemoglobin and haematocrit were significantly reduced in the control group. The blood loss was significantly low in the study group. The need for other uterotonics, blood transfusion, and duration of hospital stay, were significantly low in study group.

Conclusions: Tranexamic acid, when given prophylactically to the women with vaginal delivery who received prophylactic oxytocin, appears to reduce the blood loss effectively compared to placebo alone.

Keywords: Maternal morbidity, Normal labour, Postpartum hemorrhage, Tranexamic acid

\section{INTRODUCTION}

Labour is a physiological process, but it is often associated with morbidity and mortality, the most common cause being blood loss. ${ }^{1}$ Each year, worldwide, about 536,000 women die from causes related to pregnancy and childbirth. Almost all (99\%) of the deaths are in low and middle income countries., ${ }^{2,3}$ Postpartum haemorrhage is the most common cause of maternal death with an estimated incidence of $6 \%$ to $11 \%$ worldwide. ${ }^{4}$ Most deaths are preventable with timely administration of a uterotonic agent, is known to reduce rates of postpartum hemorrhage due to uterine atony. ${ }^{5-7}$
But in majority of cases the postpartum haemorrhage is due to retained placenta and other genital tract trauma including caesarean section. ${ }^{8-10}$ The treatment of postpartum haemorrhage may also include volume replacement for blood loss, and various surgical procedures including uterine compression sutures, arterial ligation, selective artery embolisation, intrauterine tamponade and hysterectomy. ${ }^{11,12}$ Tranexamic acid, an anti-fibrinolytic agent, reduces the incidence of bleeding in elective surgery. ${ }^{13-15}$ In addition to uterotonic agents which reduce blood loss due to uterine atony, other drugs like anti-fibrinolytic agents and recombinant factor VIIa could be used to control blood loss by effectively 
preventing postpartum coagulopathy but evidence to support a prophylactic effect on postpartum hemorrhage is weak. ${ }^{16,17}$ Because of the difficulty of randomized trials in women presenting with $\mathrm{PPH}$, the use of tranexamic acid for preventing PPH in high-risk women could be regarded as a proxy for assessing its use for treating $\mathrm{PPH}$. In particular, high-risk factors which may not be responsive to uterotonics, such as placenta previa and lacerations from instrumental delivery, may respond to tranexamic acid. ${ }^{18}$

The physiological change of blood coagulation and fibrinolytic function during pregnancy and immediately after placental delivery promotes enhancement of the fibrinolytic system that increases plasmin production and promotes degradation of fibrinogen. As a result, plasma fibrinogen level decreases during the third stage of labour and after placental delivery, and the level of fibrin/fibrinogen degradation products in the serum increases 1 hour after child birth and remains raised in the early puerperium. ${ }^{19,20}$ Hence, anti-fibrinolytics will be effective in reducing blood loss by interacting with the fibrinolytic mechanism. ${ }^{21,22}$ This study observes the blood loss reduced by tranexamic acid, an anti-fibrinolytic agent during third stage of labour.

\section{METHODS}

Three hundred pregnant women who were admitted in the antenatal or labour wards of hospitals attached to J.J.M. Medical College, Davanagere, for safe confinement at term were included in this study. One hundred and fifty patients were randomized in study group (routine prophylactic $10 \mathrm{IU}$ injection oxytocin i.v. was given to the mother as soon as the delivery of the anterior shoulder of the baby followed by injection tranexamic acid $500 \mathrm{mg}$ slow i.v. i.e. over 5 minutes), and 150 patients in control group (routine prophylactic 10 IU injection oxytocin i.v. was given to the mother as soon as the delivery of the anterior shoulder of the baby followed by placebo injection of normal saline $5 \mathrm{ml}$ slow i.v.).

\section{Study outcome}

To evaluate the efficacy of parenteral tranexamic acid in reducing blood loss during normal labour and to compare it with the amount of blood loss in patients who received placebo ( $5 \mathrm{ml}$ of normal saline) in the third stage of labour.

\section{Primary outcomes}

Reduction in blood loss after parturition, changes in blood indices in both the groups, changes in vitals.

\section{Secondary outcomes}

Requirement of maternal blood transfusion, usage of any extra uterotonics like methergin, carboprost or misoprostol, maternal and fetal complications, duration of hospital stay.

\section{Method of collection of data (including sampling procedure if any)}

Study design: It was a randomized controlled study.

Type of study and Study period: It was a time bound study took place from November 2017 to August 2019.

Study population: All women with singleton term pregnancies, fulfilling the inclusion criteria and planned for vaginal delivery were enrolled into the study.

Informed consent: All the patients and the attenders gave informed written consent.

Sample size: A total of 300 patients were included.

Sample collection procedure: Samples were collected by single blinding and by random allocation, study and control groups are decided.

Place of study: Study took place at J.J.M. Medical College, Davangere.

\section{Inclusion criteria}

Primi and second gravid. More than 38 weeks of gestation. Spontaneous or induced labour.

\section{Exclusion criteria:}

$\mathrm{HB}<8$ gm\%. Twin pregnancy. Polyhydramnios. Macrosomia. Previous history of PPH. Fibroid. Medical co-morbidities and blood disorders. Abnormal placenta, placenta previa, placental abruption, placental adhesions caused by repeated artificial abortions. Pre-eclampsia, eclampsia. PROM. Prolonged and obstructed labour. History of thromboembolic disorders. Allergy to tranexamic acid.

Detailed medical and obstetric history was taken from all the patients recruited. In each patient, the pre-delivery pulse rate, blood pressure, $\mathrm{Hb}$ gm $\%$ and $\mathrm{PCV} \%$ were noted. Labour was monitored carefully using a partogram, and augmentation was done whenever required.

\section{Measurement of blood loss}

Immediately after delivery of the baby, when all the liquor was drained, the patient was brought to the edge of the table. A BRASSS-V blood collecting drape- a disposable, conical, graduated plastic collection bag is placed under the buttocks of the patient for the blood to get collected. The amount of blood collected in the blood drape is measured. Then the patient was given preweighed pads, which was weighed 2 hours postpartum. In 
our study blood loss was measured by measuring the blood collected in the drape and by weighing the swabs before and after delivery.

Total blood loss $(\mathrm{ml})=$ blood in the drape $(\mathrm{ml})+(\mathrm{swab}$ weight post-delivery in gm - swab weight predelivery in gm) /1.056.

The side effects of the drug, if any, were noted. The patient was shifted to the post-natal ward after she passed urine. The patient's post-delivery pulse rate, blood pressure, $\mathrm{Hb}$ gm\% and PCV\% were also noted. Special attention wasgiven to any significant drop in $\mathrm{Hb}$ gm\% and PCV\% resulting in blood transfusions or parenteral iron infusions in the mother. After collecting all the data, the data were tabulated in a master chart and analysed. The descriptive measures such as mean, median and standard deviation, Standard error of mean for continuous variables were obtained. Frequencies and percentages were calculated for all categorical variables. Statistical analysis was carried for the comparison of parameters of study group against control group. $\mathrm{P}$ values were calculated using unpaired t-test.

\section{RESULTS}

From November 2017 through August 2019, we recruited 300 eligible participants and randomly assigned them to receive tranexamic acid (150 women) or placebo (150 women) and the results were analysed in the SPSS software version 16 .

The majority of patients in both the groupswere aged between 20-24 years and had their BMI between 23 and $24 \mathrm{~kg} / \mathrm{m}^{2}$. The mean age (study group-23.39 \pm 3.26 versus control group- 23.59 \pm 3.44 ) of the cases in did not differ significantly. The mean BMI was $23.21 \pm 0.58 \mathrm{~kg} / \mathrm{m}^{2}$ in the study group and $23.33 \pm 0.63 \mathrm{~kg} / \mathrm{m}^{2}$ in the control group. Seventy patients in study group and 77 patients in control group were primigravida. Eighty patients in study group and 73 patients in control group were second gravida. The parity index was comparable in both the groups. Majority of the patients $(55 \%)$ had spontaneous onset of labour in both the groups. Mean increase in pulse rate was 3.36/minute in study group and 7.46 /minute in control group. Mean fall in systolic BP was $2.66 \mathrm{mmHg}$ after 1 hour and $2.15 \mathrm{mmHg}$ after 2 hours in study group and $4.65 \mathrm{mmHg}$ after 1 hour and $4.45 \mathrm{mmHg}$ after 2 hours in control group. Mean fall in diastolic BP was 1.26 $\mathrm{mmHg}$ after 1 hour and $1.09 \mathrm{mmHg}$ after 2 hours in study group and $3.93 \mathrm{mmHg}$ after 1 hour and $3.71 \mathrm{mmHg}$ after 2 hours in control group. Mean increase in respiratory rate was $0.37 /$ minute in study group and 1.09 /minute in control group. There was a statistically significant increase in the pulse rate as well as respiratory rate and decrease in blood pressure in the control group as compared with the study group (Table 1). Mean fall in $\mathrm{SpO}_{2}$ was $0.07 \%$ in study group and $0.11 \%$ in control group (statistically not significant (Table 1).

Table 1: Variation in vital parameters.

\begin{tabular}{|c|c|c|c|}
\hline Parameters & Study group (mean \pm SEM) & Control group (mean \pm SEM) & $P$ value $(<0.05=$ significant $)$ \\
\hline \multicolumn{4}{|l|}{ Pulse rate (BPM) } \\
\hline Pre-delivery & $80.57 \pm 0.53$ & $80.05 \pm 0.57$ & \multirow{3}{*}{0.0001} \\
\hline Post-delivery1H & $83.93 \pm 0.52$ & $87.51 \pm 0.59$ & \\
\hline Change in Pulse rate & 3.36 & 7.46 & \\
\hline \multicolumn{4}{|l|}{ Systolic BP (mmHg) } \\
\hline Pre-delivery & $119.39 \pm 0.57$ & $118.45 \pm 0.57$ & \multirow{3}{*}{0.001} \\
\hline Post-delivery $1 \mathrm{H}$ & $116.40 \pm 0.57$ & $113.80 \pm 0.52$ & \\
\hline Change in Sys BP-1H & 2.26 & 4.65 & \\
\hline Post-delivery $2 \mathrm{H}$ & $117.24 \pm 0.57$ & $114.00 \pm 0.52$ & \multirow{2}{*}{0.008} \\
\hline Change in Sys BP-2H & 2.15 & 4.45 & \\
\hline \multicolumn{4}{|l|}{ Diastolic BP (mmHg) } \\
\hline Pre-delivery & $77.01 \pm 0.38$ & $75.56 \pm 0.48$ & \multirow{5}{*}{$\begin{array}{l}0.02 \\
0.04\end{array}$} \\
\hline Post-delivery $1 \mathrm{H}$ & $75.75 \pm 0.39$ & $71.63 \pm 0.47$ & \\
\hline Change in dia BP-1H & 1.26 & 3.93 & \\
\hline Post-delivery $2 \mathrm{H}$ & $75.92 \pm 0.37$ & $71.85 \pm 0.46$ & \\
\hline Change in dia BP-2H & 1.09 & 3.71 & \\
\hline \multicolumn{4}{|c|}{ Respiratory rate/minute } \\
\hline Pre-delivery & $15.87 \pm 0.12$ & $15.13 \pm 0.15$ & \multirow{3}{*}{0.04} \\
\hline Post-delivery & $16.23 \pm 0.08$ & $16.22 \pm 0.16$ & \\
\hline Change in respiratory rate & 0.36 & 1.09 & \\
\hline \multicolumn{4}{|l|}{$\mathrm{SpO}_{2} \%$} \\
\hline Pre-delivery & $97.62 \pm 0.08$ & $97.38 \pm 0.11$ & \multirow{3}{*}{0.54} \\
\hline Post-delivery & $97.55 \pm 0.08$ & $97.27 \pm 0.10$ & \\
\hline Change in SPo2 & 0.07 & 0.11 & \\
\hline
\end{tabular}


The mean fall in haemoglobin was $0.672 \mathrm{gm} \%$ in study group and $1.24 \mathrm{gm} \%$ in control group. Mean fall in haematocrit was $1.93 \%$ in study group and $3.49 \%$ in control group. The post-delivery haemoglobin and haematocrit were significantly reduced in the control group as compared to the study group. The mean blood loss at the end of 2 hours was $191 \mathrm{ml}$ in the study group and $277 \mathrm{ml}$ in the control group. The blood loss was significantly low in the study group compared to the control group (Table 2).

Table 2: Variation in blood indices.

\begin{tabular}{|c|c|c|c|}
\hline Parameters & Study group (mean \pm SEM) & Control group (mean \pm SEM) & P value $(<0.05=$ significant $)$ \\
\hline \multicolumn{4}{|l|}{ Haemoglobin (gm\%) } \\
\hline Pre-delivery & $11.46 \pm 0.10$ & $11.63 \pm 0.18$ & \multirow{3}{*}{$<0.0001$} \\
\hline Post-delivery & $10.78 \pm 0.10$ & $10.38 \pm 0.10$ & \\
\hline Difference & \pm 0.67 & \pm 1.28 & \\
\hline \multicolumn{4}{|l|}{ PCV (\%) } \\
\hline Pre-delivery & $35.11 \pm 0.29$ & $35.32 \pm 0.30$ & \multirow{3}{*}{$<0.0001$} \\
\hline Post-delivery & $33.18 \pm 0.30$ & $31.83 \pm 0.32$ & \\
\hline Difference & \pm 1.93 & \pm 3.49 & \\
\hline Total blood loss (ml) & $191 \pm 3.02$ & $277 \pm 4.02$ & $<0.0001$ \\
\hline
\end{tabular}

Table 3: Usage of additional uterotonics.

\begin{tabular}{|lllll|}
\hline Additional & \multicolumn{2}{c|}{ Study group } & \multicolumn{2}{c|}{ Control group } \\
uterotonics & No. & \% & No. & \% \\
\hline Yes & 11 & 7.3 & 42 & 28 \\
\hline No & 139 & 93 & 108 & 72 \\
\hline
\end{tabular}

$\mathrm{P}$ value $<0.001$ (significant)

The mean duration of third stage of labour was $4.71 \mathrm{~min}$ in the study group and $4.68 \mathrm{~min}$ in the control group. There was no influence of the drug in the duration of third stage. There was a significant difference in the requirement of uterotonics between the groups. $11(7 \%)$ patients in the study group needed additional uterotonics (carboprost and methergin), whereas 42 (28\%) patients in the control group needed additional uterotonics. 12 $(8.0 \%)$ of the patients in the control group needed blood transfusion compared to $26(17 \%)$ in the study group. There was a significant difference in the need for blood transfusion between the two groups (Table 4). The patients in both the groups, who had PPH, lost almost 450-600 $\mathrm{ml}$ of blood.

Table 4: Maternal blood transfusion.

\begin{tabular}{|lllll|}
\hline Blood & \multicolumn{2}{c|}{ Study group } & \multicolumn{2}{c|}{ Control group } \\
transfusion & No. & \% & No. & \% \\
\hline Yes & 12 & 8.0 & 26 & 17 \\
\hline No & 138 & 92 & 124 & 83 \\
\hline
\end{tabular}

$\mathrm{P}$ value $<0.001$ (significant)

$14(9 \%)$ of the patients in the control group had to stay for more than 3 days at hospital post-delivery compared to $6(4 \%)$ in the study group (Table 5). There was no significant difference in maternal complications such as vomiting, diarrhoea or fever between the two groups.
Table 5: Duration of stay at hospital post-delivery.

\begin{tabular}{|lllll|}
\hline \multirow{2}{*}{ Duration of stay } & \multicolumn{2}{c|}{ Study group } & \multicolumn{2}{c|}{ Control group } \\
\cline { 2 - 5 } & No. & \% & No. & $\%$ \\
\hline 3 3 days & 144 & 96 & 136 & 91 \\
\hline >3 days & 6 & 4 & 14 & 9 \\
\hline
\end{tabular}

$P$ value $<0.001$ (significant)

\section{DISCUSSION}

As obstetric blood loss contributes to one fourth of global maternal death, death resulting from PPH can be avoided. Intravenous oxytocin is the drug of choice for postpartum haemorrhage other uterotonics like misoprostol, ergometrine, carboprost may also be used for uterine atony. ${ }^{23,24}$ Apart from uterine atony, retained placenta or placental abnormalities, and coagulopathy were the other causes for the $\mathrm{PPH} .{ }^{25}$ As the fibrinolytic system gets activated after placental delivery, anti-fibrinolytic agents can be used to reduce obstetric blood loss. As prevention is always better than cure regarding $\mathrm{PPH}-$ an antifibrinolytic agent tranexamic acid $500 \mathrm{mg}$ slow intravenously was used prophylactically in our study to observe its efficacy in reducing blood loss during and after vaginal birth.

In our study, mean post-delivery increase in pulse rate was 3.36/minute in study group and 7.46/minute in control group. The mean fall in systolic BP was 2.15 $\mathrm{mmHg}$ in study group and $4.45 \mathrm{mmHg}$ in control group. Mean fall in diastolic BP was $1.09 \mathrm{mmHg}$ in study group and $3.71 \mathrm{mmHg}$ in control group, 2 hours post-delivery. There was a significant fall $\mathrm{BP}$ and rise in pulse rate. There was a statistically significant change in vital parameters which are in concurrence with similar studies carried out earlier. ${ }^{26,27}$ There was a statistically significant fall in $\mathrm{Hb} \%$ in the control group as compared to the study group in Mean blood loss from the time of delivery to 2 
hours was $191 \mathrm{ml}$ in study group and $277 \mathrm{ml}$ in control group. These results were in agreement with previous studies carried out elsewhere. ${ }^{28-30}$

Our study demonstrated that $28 \%$ of the patients in the control group needed additional uterotonics compared to only $7 \%$ in the study group, which was statistically significant $(p<0.001)$. Thus, significant decrease in the need for additional uterotonics has been reiterated, as also noted in previous trials. ${ }^{31} 12$ patients $(8 \%)$ in the study group compared to 26 patients $(17 \%)$ in the control group needed blood transfusion which has also been observed in erstwhile trails. ${ }^{32,33} 6$ patients in the study group had to stay for more than 3 days compared 14 patients in control group.

\section{CONCLUSION}

Tranexamic acid injection, an anti-fibrinolytic agent when given prophylactically after the delivery of the anterior shoulder, by intravenous route appears to reduce the blood loss during normal labour effectively. World Health Organization guidelines recommend administration of tranexamic acid in treatment of PPH and trauma. The adoption of WHO guidelines for using uterotonic agents and prophylactically administering Tranexamic acid may significantly reduce the number of PPH incidents. There is a minimal possibility of increase in the risk of thromboembolism but was not observed in our study. So, further studies are also needed to support its efficacy.

\section{ACKNOWLEDGMENTS}

We would like to thank Dr. Kiran K. Nagothu Ph.D. for his help in critical reading and preparing the manuscript.

Funding: No funding sources

Conflict of interest: None declared

Ethical approval: The study was approved by the Institutional Ethics Committee

\section{REFERENCES}

1. Chaudhary M, Shah M, Makwana N. Placental cord drainage during third stage of labour: a randomized control trial at a tertiary care centre. Int $\mathrm{J}$ Reprod Contracept Obstet Gynecol. 2020;9(3):1143-7.

2. Calvert C, Thomas SL, Ronsmans C, Wagner KS, Adler AJ, Filippi V. Identifying regional variation in the prevalence of postpartum hemorrhage: a systematic review and meta-analysis. PLoS One. 2012;7(7):e41114.

3. Trends in maternal mortality: 2000 to 2017 : estimates by WHO, UNICEF, UNFPA, World Bank Group and the United Nations Population Division. Geneva: World Health Organization; 2019.

4. Maswime S, Buchmann E. A systematic review of maternal near miss and mortality due to postpartum hemorrhage. Int J Gynaecol Obstet. 2017;137(1):1-7.
5. WHO recommendations for the prevention and treatment of postpartum haemorrhage. Geneva: World Health Organization; 2012. Available from: http://apps.who.int/iris/bitstream/handle/10665/7541 1/9789241548502_eng.pdf. Accessed on 5 November 2018.

6. Begley CM, Gyte GM, Devane D, Mc-Guire W, Weeks A. Active versus expectant management for women in the third stage of labour. Cochrane Database Syst Rev. 2015;3:CD007412.

7. Sentilhes L, Merlot B, Madar H, Sztark F, Brun S, Deneux-Tharaux C, et al. Postpartum haemorrhage: prevention and treatment. Expert Rev Hematol. 2016;9:1043-61.

8. Coviello EM, Grantz KL, Huang C, Kelly TE, Landy HJ. Risk factors for retained placenta. Am J Obstet Gynecol. 2015;213:864.e1-11.

9. WOMAN Trial Collaborators. Effect of early tranexamic acid administration on mortality, hysterectomy, and other morbidities in women with postpartum haemorrhage (WOMAN): an international, randomized, double blind, placebo controlled trial. Lancet. 2017;389:2105-16.

10. Prata N, Bell S, Weidert K. Prevention of postpartum hemorrhage in low-resource settings: current perspectives. Int J Wom Health. 2013;5:737-52.

11. Matsuzaki S, Jitsumori M, Hara T, Matsuzaki S, Nakagawa S, Miyake T, et al. Systematic review on the needle and suture types for uterine compression sutures: a literature review. BMC Surg. 2019;19:196.

12. Miller AD, Oner C, Kosik ES, McCalla S. Obstetric hemorrhage current management and usefulness of protocols, checklist, drills. Curr Obstet Gynecol Rep. 2016;5:355-64.

13. Sentilhes L, Lasocki S, Ducloy-Bouthors AS, Dreyfus M, Perrotin F, Goffinet F, et al. Tranexamic acid for the prevention and treatment of postpartum haemorrhage. Br J Anaesth. 2015;114:576-87.

14. Ker K, Edwards P, Perel P, Shakur H, Roberts I. Effect of tranexamic acid on surgical bleeding: systematic review and cumulative meta-analysis. BMJ. 2012;344:e3054.

15. Myles PS, Smith JA, Forbes A. Tranexamic acid in patients undergoing coronary-artery surgery. N Engl J Med. 2017;376:136-48.

16. Gai MY, Wu LF, Su QF, Tatsumoto K. Clinical observation of blood loss reduced by tranexamic acid during and after caesarean section: a multi center randomized trial. Eur J Obstet Gynecol Reprod Biol. 2004;112(2):154-7.

17. Gayet-Ageron A, Prieto-Merino D, Ker K, Shakur H, Ageron FX, Roberts I, et al. Effect of treatment delay on the effectiveness and safety of antifibrinolytics in acute severe haemorrhage: a meta-analysis of individual patient-level data from 40138 bleeding patients. Lancet. 2018;391(10116):125-32.

18. Yang $\mathrm{H}$, Zheng S, Shi C. Clinical study on the efficiency of tranexamic acid in reducing postpartum blood loss- a randomized multicentre trial. Zhonghua Fu Chan Zazhi. 2001;36(10):590-2. 
19. Matsunaga S, Takai Y, Seki H. Fibrinogen for the management of critical obstetric hemorrhage. J Obstet Gynaecol Res. 2019;45(1):13-21.

20. Peitsidis P, Kadir RA. Tranexamic acid in pregnancy and postpartum. Expert Opin Pharmacother. 2011;12(4):503-16.

21. Leduc D, Senikas V. Active management of third stage of labour: prevention and treatment of PPH. J Obstet Gynaecol Can. 2009;31(10):980-93.

22. Updated WHO Recommendation on Tranexamic Acid for the Treatment of Postpartum Haemorrhage. Geneva: World Health Organization; 2017.

23. The prevention and treatment of postpartum haemorrhage: what do we know, and where do we go to next? BJOG. 2015:122(2):202-10.

24. Anderson JM, Etches D. Prevention and management of postpartum hemorrhage. Am Fam Phys. 2007;75(6):875-82.

25. Novikova N, Hofmeyr GJ. Tranexamic acid for preventing postpartum haemorrhage. Cochrane Database Syst Rev. 2010;(7):CD007872.

26. Roy P, Sujatha MS, Bhandiwad A, Biswas B. Role of tranexamic acid in reducing blood loss in vaginal delivery. J Obstet Gynaecol India. 2016;66(1):24650

27. Soltani H, Hutchon DR. Timing of prophylactic uterotonics for third stage of labour after vaginal birth. Cochrane Database Syst Rev. 2010;4(8):CD006173.

28. Tesseir V, Pierre F. Risk of PPH during labour and clinical and pharmacological prevention. J Obstet Gynaecol. 2004;33:4529-56.

29. Sentilhes L, Winer N, Azria E, Sénat MV, Le Ray C, Vardon D, et al. Tranexamic acid for the prevention of blood loss after vaginal delivery. N Engl J Med. 2018;379(8):731-42.

30. Sekhavat L, Tabatabaii A. Efficacy of tranexamic acid in reducing blood loss after caesarean section. $\mathbf{J}$ Matern Fet Neonat Med. 2009;22(1):72-5.

31. Litch JA. Program for appropriate technology and health. Seattle: AMTSL; 2004:132.

32. Gokhan. Routine practice of using tranexamic acid in AMTSL. NCT01338454, Bakirkoy; 2011.

33. Zargar M, Nikbakht R, Ahmadi M. The effect of tranexamic acid on preventing post-partum hemorrhage due to uterine atony: a triple-blind randomized clinical trial. Curr Clin Pharmacol. 2018;13:136-9.

Cite this article as: Ginjupalli A, Anuradha SN, Joshi SD. Prophylactic use of tranexamic acid for reducing postpartum hemorrhage in vaginal delivery. Int J Reprod Contracept Obstet Gynecol 2021;10:1654-9. 